\title{
Is there still a role for pubovaginal slings in the treatment of SUI in the era of mid-urethral slings?
}

\author{
Stephen S. Steele, MD, FRCSC \\ Department of Urology, Queen's University, Kingston, ON
}

See related article on page 36 .

Cite as: Can Urol Assoc J 2012;6(1):41. http://dx.doi.org/10.5489/cuaj.12011

$\mathrm{T}$

he treatment of female stress urinary incontinence (SUI) has evolved over the last decade. ${ }^{1}$ Traditional surgeries for SUI, such as the Burch colposuspension and pubovaginal slings, have slowly been supplanted by mid-urethral slings (MUS). In some centres, retropubic surgeries have become almost obsolete. This has not had a negative impact on the surgical treatment of female SUI. In fact, various databases have demonstrated almost a threefold increase in the overall number of incontinence procedures performed. ${ }^{2,3}$ The rationale for this shift in surgical procedure and for the increase in surgical volume appears to be related to decreased complication rates, shorter operative time and the simplicity of MUS surgery without compromising objective and subjective cure rates. ${ }^{4,5}$

Are surgical procedures, such as autologous rectus fascia pubovaginal sling (AF-PVS), history or do they still have a role in female SUI. Welk and Herschorn support that AF-PVS can be a vital tool in the treatment of complex SUI. ${ }^{1}$ They describe an extremely complex patient population with recurrent SUI that underwent AF-PVS at their centre. Over half of the patient population had mesh erosions, urethral diverticuli or trauma. The remaining patients underwent on average 2 prior surgical procedures to treat their SUI before undergoing an AF-PVS. Their surgical outcomes and patient satisfaction were quite commendable considering the complexity of the patient population. Average pad use decreased from 5 pads per day (PPD) preoperatively to 1 PPD postoperatively. Moreover, the patients' rating of their overall quality of life was reasonable $(62 \%$ scored from 4 [mixed] to 7 [delighted]).

There is, however, an underlying concern from an education perspective that permeates throughout the paper concerning the shift to MUS. ${ }^{1}$ Although AF-PVS, Burch colposuspension and other retropubic surgeries may be indicated in

various surgical settings for female SUI, graduating urology residents may not have the surgical acumen and experience to perform them. Wu and colleagues found that the number of retropubic suspension surgeries in the United States fell from $52.8 \%$ of SUI procedures in 1998 to $13.8 \%$ in $2007 .^{2}$ As the number of pubovaginal slings performed in academic centres continues to fall, graduating urology residents may not be adequately exposed to these procedures to perform them competently and safely. As a result, these operations have the potential to become largely historical procedures or isolated in tertiary referral centres. Alarms have already been sounded concerning graduating Canadian urology residents' surgical exposure to open radical nephrectomy and open radical retropubic prostatectomy. ${ }^{6}$ Perhaps these "complex surgical incontinence surgeries," need to be added to that list.

Competing interests: None declared.

This paper has been peer-reviewed.

\section{References}

1. Welk BK, Herschorn S. The autologous fascia pubovaginal sling for complicated female stress incontinence. Can Urol Assoc J 2012;6:36-40. http://dx.doi.org/10.5489/cuaj.11117

2. Wu JM, Gandhi MP, Shah AD, et al. Trends in inpatient urinary incontinence surgery in the USA, 19982007. Int Urogynecol J 2011;22:1437-43. http://dx.doi.org/10.1007/s00192-011-1509-x

3. Oliphant $S S$, Wang $L$, Bunker $C H$, et al. Trends in stress urinary incontinence inpatient procedures in the United States, 1979-2004. Am J Obstet Gynecol 2009;200:521.el-6.

4. Sharifiaghdas F, Mortazavi N. Tension-free vaginal tape and autologous rectus fascia pubovaginal sling for the treatment of urinary stress incontinence a medium term follow-up. Med Princ Pract 2008; 17:209-14. http://dx.doi.org/10.1159/000117794

5. Jeon MJ, Jung HJ, Chung SM, et al. Comparison of the treatment outcome of pubovaginal sling, tension-free vaginal tape, and transobturator tape for stress urinary incontinence with intrinsic sphincter deficiency. Am J Obstet Gynecol 2008; 199:76.el-4.

6. Mamut AE, Afshar K, Mickelson JJ, et al. Surgical case volume in Canadian urology resident: a comparison of trends in open and minimally invasive surgical experience. J Endourol 2011;25:1063-7. http://dx.doi. org/10.1089/end.2010.0304

Correspondence: Dr. Stephen Steele, Assistant Professor, Department of Urology, Queen's University, 76 Stuart St, Kingston, 0N K7L 2V7; steeles@kgh.kari.net 